\title{
LIVER FUNCTION IN CONGESTIVE HEART FAILURE
}

\author{
BY NORMAN JOLLIFFE
}

(From the Departments of Medicine and Physiology of New York University Medical College and the Third (New York University) Medical Division of Bellevue Hospital)

(Received for publication October 23, 1929)

\section{INTRODUCTION}

Jaundice, varying from a slight yellowish tinting of the sclerae to a pronounced general icterus, is a common occurrence in congestive heart failure. A review of the literature leaves one with the impression that it is seen most frequently in patients with long standing congestive heart failure, particularly in failure associated with mitral and tricuspid valvular disease and in failure associated with auricular fibrillation. It repeatedly has been shown that the jaundice occurring in the course of congestive heart failure is due to an increase in serum bilirubin $(1,2,3,4,5,6,7,8)$. Matthes (9) in his "Differential Diagnosis" noted that jaundice in congestive heart failure is often characterized by its sudden appearance. Schottmüller (10), Eppinger (3), and Libman (11), noted that the sudden appearance of the icterus was often associated with pulmonary infarction. Resnik and Keefer $(12,13)$ after a clinical and experimental study of jaundice following pulmonary infarction conclude that "anoxemia may depress the function of livers already damaged to such an extent that the bilirubin content of the blood strikingly increases." They note that in every case of 'cardiac' jaundice there is anatomical and functional impairment of the liver cells. They agree with Fishberg (6) that patients with congestion of the liver may have only a slight increase in serum bilirubin. Conversely, patients may have a high serum bilirubin and their livers may be barely palpable. The size of the liver may not give a correct idea of either its anatomical or functional impairment.

Eppinger (3) showed that there is an increased blood destruction and bilirubin formation in congestive heart failure. Resnik and Rich (14) were unable to obtain conclusive evidence that local extravasations of 
blood in patients with severe congestive heart failure caused sudden increases in serum bilirubin. Eppinger has described bile thrombi in the liver of chronic passive congestion and suggested that these cause a certain degree of obstructive jaundice. He admitted that these thrombi could not be a very important factor as they were found with difficulty or were entirely absent even in the presence of marked jaundice.

Meakins (15) made the observation that jaundice in circulatory failure was limited to the edema free portions of the body in six cases studied. He thinks it probable that there are two types of jaundice in circulatory failure. One, analogous to the so-called hemolytic variety and the other to the obstructive type. In the first type Meakins corroborates Resnik and Keefer in that any increase in anoxemia would be expected to accentuate the impairment of liver function. Page (16) reports two cases of ipsolateral edema and contralateral jaundice on the basis of congestive heart failure following hemiplegia. He considers any explanation of jaundice occurring only in edema free portions of the body to be speculative.

The impairment of the pigment function of the liver in congestive heart failure has been extensively studied. The impairment of other functions has not received equal investigation. Much of the work which has been done was directed toward establishing the value of certain functional tests. Wallace and Diamond (17) in eleven cases of congestive failure found the urobilinogen increased in all. Piersol and Rothman (18) in a group of patients having congestive heart failure with ascites found the urobilinogen constantly increased, but the bromsulphalein test "not of any great importance." Serby and Bloch (19) studied nine patients with heart disease, five of whom had an enlarged liver, but in only one was there a retention of bromsulphalein. Epstein, Delprat and Kerr (20) studied the elimination of rose bengal in seven cases of congestive heart failure. All were normal except one with marked anasarca. Ottenberg, Rosenfeld and Goldsmith (21) using phenoltetrachlorphthalein found a retention of more than five per cent of the dye in ten of fourteen cases of heart failure. The levulose tolerance.test apparently has not been extensively examined in congestive heart failure. Kind (22) found that of three patients with congestive failure two had slight impairment of the levulose 
tolerance. Only one of these patients showed liver impairment if the criteria of Tallerman (23) are used.

The purpose of the present study of congestive failure was to determine:

1. The frequency of clinical jaundice.

2. The type of jaundice.

3. The frequency of impairment of other functions of the liver.

4. The occurrence of a characteristic type of liver dysfunction.

5. The parallelism between the degree of heart failure and impairment of liver function.

6. The duration of the liver dysfunction.

\section{METHOD}

The investigation described here extended over a period of five months (December, 1928, to April, 1929, inclusive). During this time 231 patients with congestive heart failure were admitted to the wards of the Third (New York University) Medical Division of Bellevue Hospital. These patients were frequently observed in daylight for the presence of jaundice. Of this group sixteen were selected for an intensive study. The type of patient selected was, as a rule, one with marked edema who had not received digitalis for three weeks, and who was not too ill to allow a control period of at least four days. The group was so selected as to include some patients in their first attack of failure, some in their second attack of failure, and some in their third, or later attacks of failure. The selection of patients was such as to include a variety of etiological factors. All of the patients developing jaundice were studied except one who died within a few hours of admission. Table 1 gives the clinical data on each of the patients studied. For a control group, three patients with organic heart disease giving no history of congestive failure or lessened cardiac reserve were studied.

The patients were kept in bed on a limited fluid intake and a uniform diet. Daily observations were made on the ventricular rate, pulse rate, weight, water intake and urine output. The patients were observed during a control period of from four to eleven days. During this period frequent observations were made of the amount and distribution of the edema, the presence of jaundice and its distribution, the 
presence of ascites, and the size of the liver measured from the ensiform. During this period the various liver function tests were carried out. At the end of the control period moderate doses of digitalis leaf were given till therapeutic results or mild toxic symptoms developed. The subjects were then put on a daily maintenance dose of digitalis. The liver function tests were repeated during the disappearance of the edema and again after the patients were edema free.

\section{The liver function tests used}

1. Daily urobilinogen determinations were made by the method of Wallace and Diamond (17) on a freshly voided specimen of urine collected at approximately the same time each morning. The recognition of urobilinogen in dilutions of one in twenty or less was considered normal.

2. A qualitative bilirubin determination was made on the same specimen of urine examined for urobilinogen.

3. The serum bilirubin was determined qualitatively and quantitatively, Hall's (24) modification of the van den Bergh technique was used. The serum bilirubin was judged by the following criteria: $0.50 \mathrm{mgm}$. per cent or less-normal; $0.51 \mathrm{mgm}$. to $2.00 \mathrm{mgm}$. per cent -latent jaundice; over $2.00 \mathrm{mgm}$. per cent- clinical jaundice (24).

4. For the dye test the original bromsulphalein method of Rosenthal and White (25) was followed. The percentage of the dye in the blood stream at the end of thirty minutes was determined. More than faint traces at this time were considered as abnormal.

5. The levulose tolerance test was performed at least once during the control period and again after disappearance of the edema, using the technique of Tallerman (23). Prior to the levulose tolerance test the patients were fasted for fourteen hours or more. After taking a fasting blood sample, 30 to 50 grams of levulose dissolved in $250 \mathrm{cc}$. of water were given by mouth. The quantity of levulose administered was varied according to the weight of the patient (23). Blood samples were withdrawn at 30,60 and 120 minute intervals. The protein was precipitated with tungstic acid within five minutes of taking the sample. Sugar was determined by the method of Folin and Wu (26). A Klett bio-colorimeter was used, and all readings made by the same individual. The same amount of levulose given each patient on first 
test was given on repetition of the test. Tallerman's criterion of a rise of at least $30 \mathrm{mgm}$. in blood sugar, providing the blood sugar level reached $135 \mathrm{mgm}$. per cent was considered ąs abnormal.

6. In addition to these tests of liver function, the blood non-protein and urea nitrogen, the bleeding time, the coagulation time, the fragility of the red blood corpuscles and Widal's hemoclastic test were determined on most of the cases. The results obtained from Widal's hemoclastic test will be reported in another paper. The results of the other tests are not reported in this study because our findings were, allowing for experimental error, normal.

\section{The grouping of cases}

Three patients $(1,2,3)$ had definite organic heart disease but gave no history of congestive failure or lessened cardiac reserve. These cases comprise the "control group" (table 1). The sixteen patients (4 to 19 inclusive) who had congestive heart failure comprise the "congestive failure group." In twelve patients ( 8 to 19 inclusive) it was possible to study liver function during a control period, during improvement, and after disappearance of the edema. These cases comprise the "improved group."

\section{RESULTS}

\section{Urobilinogen}

The control group patients were consistently normal. Two of the three fatal cases had at some time an increase in urobilinogen, and the unimproved case was almost always above a dilution of $1: 30$. Of the four patients who were jaundiced $(4,5,8,9)$ every one had an increase in urobilinogen. Of the sixteen patients in congestive failure nine (56 per cent) had at some time or other an increase in urobilinogen. Three patients had marked ascites $(9,12,14)$ as evidenced by a fluid wave. Two of these $(9,14)$ had an increase in urobilinogen. Wallace and Diamond (17) and Piersol and Rothman (18) found the urobilinogen constantly increased in congestive heart failure. Only two cases $(16,18)$ of the improved group showed an increase of urobilinogen following digitalization. These two cases returned to normal on the fifth and fifteenth day following administration of digitalis. Figure $1 \mathrm{e}$ 


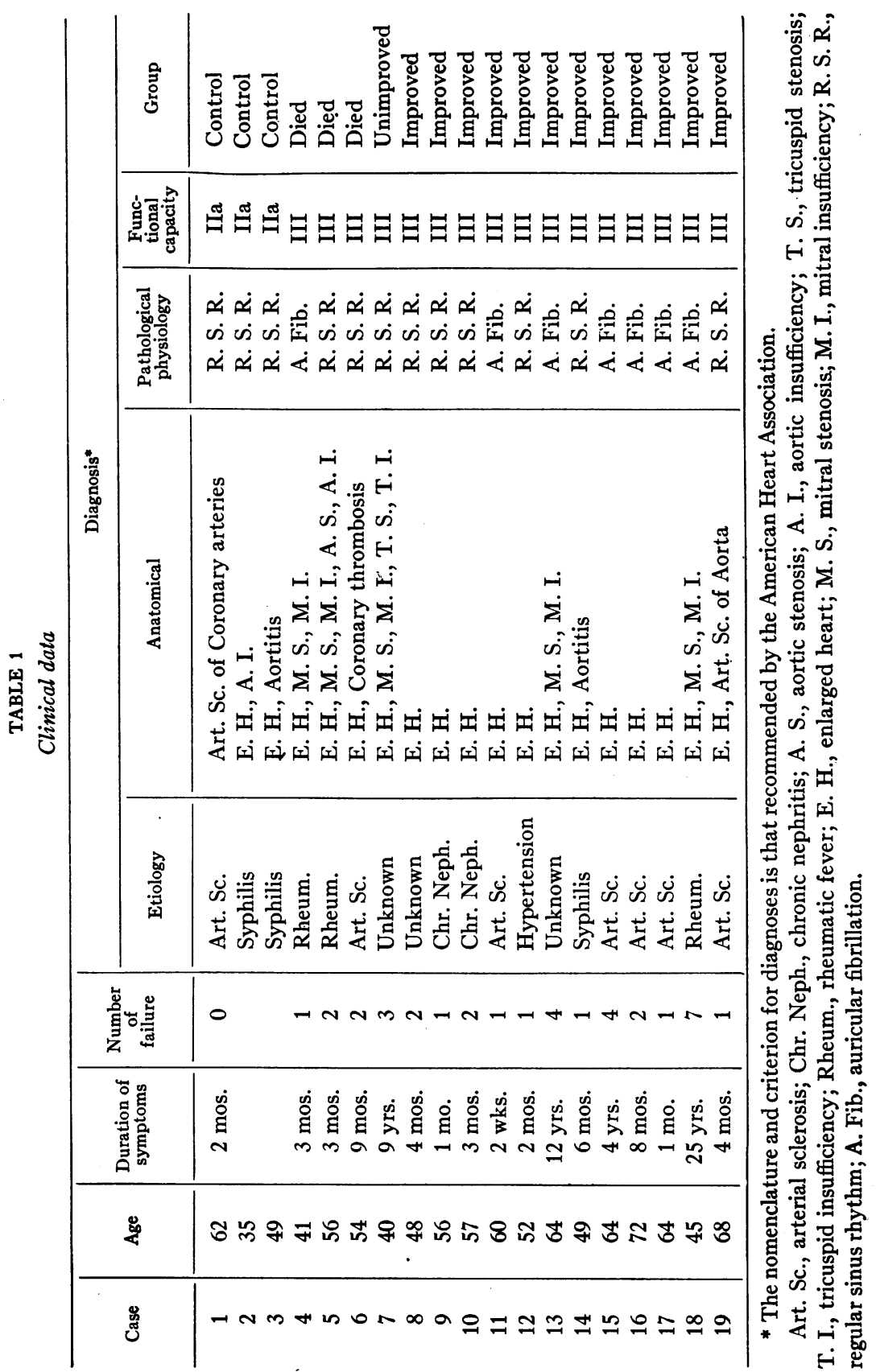


shows the composite urobilinogen curve in the improved group of cases. It will be noted that the trend of the curve is persistentlydownward from the beginning of the control period.

On reviewing the results of the urobilinogen determinations more than half of the cases of congestive heart failure had an increase in urobilinogen. The results seem to show a relation between the occurrence of clinical jaundice and an increase in urobilinogen. There is little correlation between an increase in urobilinogen and prognosis or presence of ascites.

\section{Serum bilirubin}

The serum bilirubin was within normal limits in all the control patients. Of the sixteen patients with congestive heart failure thirteen (81 per cent) had an increase in serum bilirubin over the accepted normal of $0.50 \mathrm{mgm}$. per cent. Of the three patients $(6,14,19)$ who were within normal limits one died (6). This patient had been in almost constant heart failure for nine months, had only slight edema of the ankles, moderate enlargement of the liver, but marked pulmonary stasis and intense dyspnoea. The only abnormal liver function test was a retention of 5 per cent bromsulphalein. He was a mild diabetic, therefore no conclusions could be drawn from the levulose tolerance test. The serum bilirubin in the three fatal cases (fig. 2) showed a marked increase in two $(4,5)$, both being clinically jaundiced. The unimproved case (7) had a moderate elevation of serum bilirubin at times approaching the level of clinical jaundice. The small amount of edema present at the beginning of the observation disappeared. The liver however remained near the level of the umbilicus, and was very tender and pulsating. A diagnosis of organic tricuspid valvular disease was made on this patient.

Five (2.1 per cent) of the 231 cases of congestive tailure under observation developed actual clinical jaundice as determined by the naked eye. Of the five patients, four $(4,5,8,9)$ were included in this study. The two who died had rheumatic mitral valvular disease, while the two who recovered had no demonstrable valvular disease. The four patients who developed jaundice presented interesting variations in the van den Bergh reaction. Two $(5,9)$ had an immediate direct reaction and bile in the urine. When the serum bilirubin (9) fell 


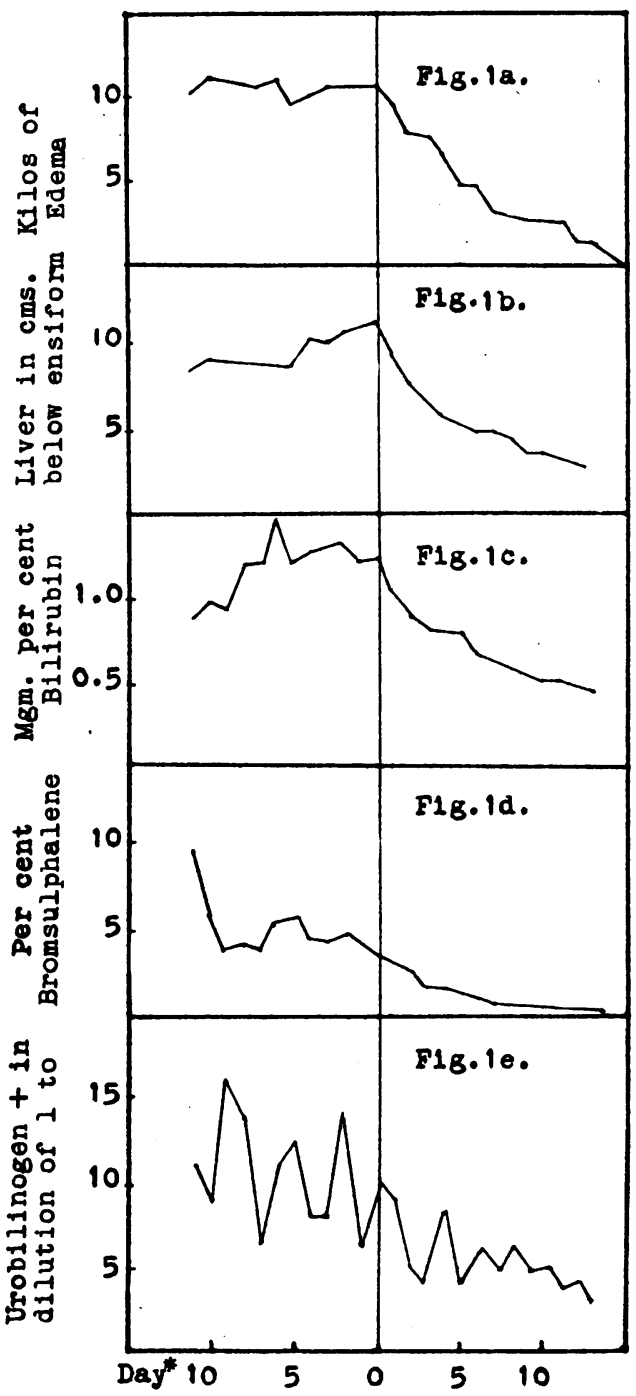

Frg. 1. Composite Curves in the Improved Group

a. Amount of edema. b. Size of the liver. c. Serum bilirubin. d. Retention of bromsulphalein at end of thirty minutes. e. Urine urobilinogen.

* The day labeled 0 is the day on which the patient first received digitalis. The numbers to the left of 0 indicate the number of days before the first dose of digitalis (control period). The numbers to the right of 0 indicate the number of days after the first dose of digitalis.

† The weight of edema was estimated by subtracting the edema free weight of the patient from the weights recorded while edematous. 
below $2.00 \mathrm{mgm}$. per cent the reaction became delayed. The other two jaundiced patients $(4,8)$ had a delayed direct van den Bergh reaction and no bile in the urine though the level of serum bilirubin far exceeded $2.00 \mathrm{mgm}$. per cent. All but one (11) who had latent jaundice had a delayed direct van den Bergh reaction. The exception

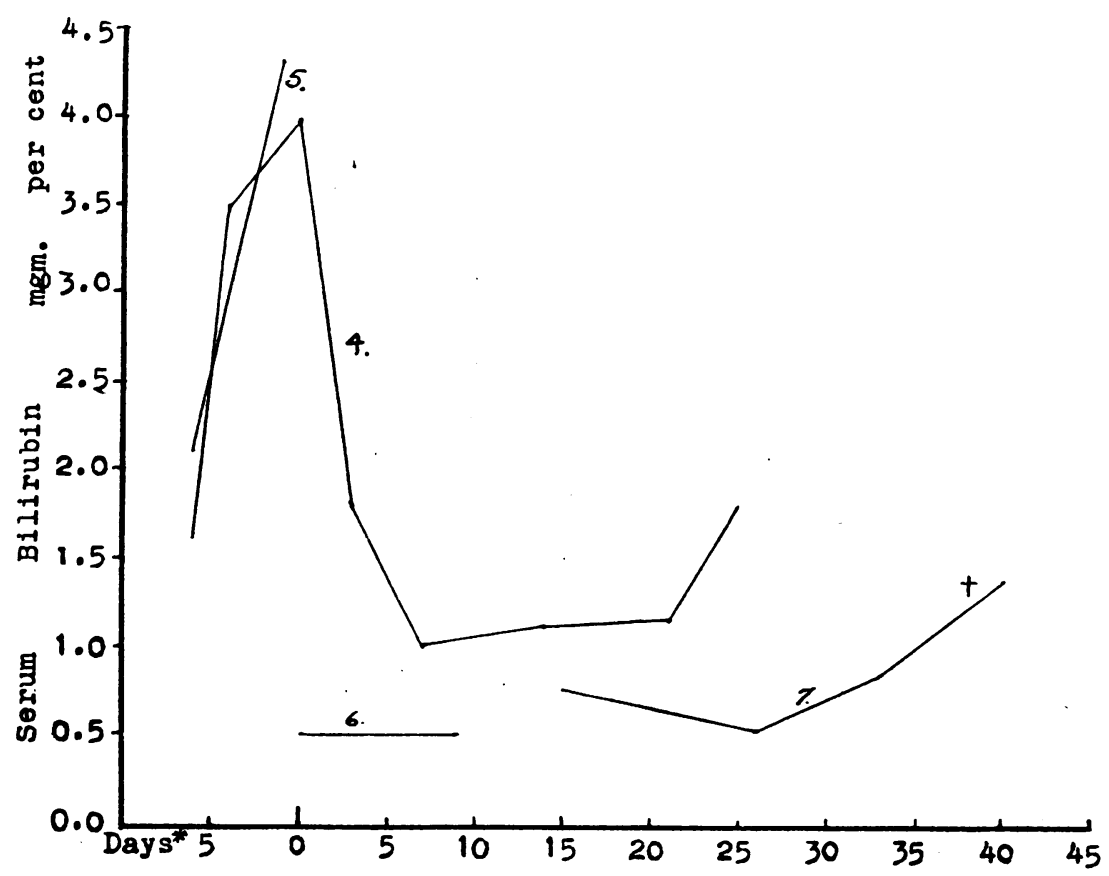

Fig. 2. Serum Bilirubin in the fatal and Unimproved Group

* The day labeled 0 is the day on which the patient first received digitalis. The numbers to the left of 0 indicate the number of days before the first dose of digitalis (control period). The numbers to the right of 0 indicate the number of days after the first dose of digitalis.

$\dagger$ Serum bilirubin remained approximately at this level during the remainder of the observation.

had only the indirect reaction. In three of the jaundiced patients $(4,5,8)$ the distribution was at first noted by Meakins in that the jaundice only involved the edema free portions of the body. In the fourth case of jaundice this fact was not noted.

All but two patients $(15,19)$ of the improved group had some increase 
in serum bilirubin. This varied from a slight increase to clinical jaundice. The composite curve of this group (fig. $1 \mathrm{c}$ ) shows an elevated serum bilirubin, though the mean value lies below the level of clinical jaundice during the control period. The curve falls very sharply following administration of digitalis. The bilirubin curve is practically identical with the composite curves showing the edema (fig. $1 \mathrm{a}$ ) and the size of the liver (fig. $1 \mathrm{~b}$ ) in the same group of cases.

\section{Bromsulphalein}

Sixty-two bromsulphalein determinations were made on the nineteen patients at various times. In two patients $(1,3)$ of the control group there was no retention of the dye, while one (2) showed a retention of 5 per cent on two occasions. It should be noted that this patient was a colored male who in addition to luetic heart disease had a liver which was palpable $6 \mathrm{~cm}$. below the ensiform and which was definitely lobular in shape. Twelve of the sixteen patients in the congestive failure group ( 75 per cent) showed a retention of the dye varying from 5 to 20 per cent during the control period. Every one of the fatal cases had some retention of the dye, and in one fatal case a retention of 5 per cent of the dye was the only abnormal liver function test. The improved group showed in eight (66 per cent) a retention of the dye varying from 5 to 15 per cent during the control period. Every one of these patients returned to normal following digitalization. The composite curve of this group (fig. $1 \mathrm{~d}$ ) shows a progressive fall in dye retention from the beginning of the control period. In this respect it resembles the composite curve of the urobilinogen in the same group.

\section{Levulose tolerance test}

The levulose tolerance test was performed thirty-nine times on the nineteen patients in this study. For controls the test was done on fourteen convalescent patients without demonstrable liver disease. The composite curve of the convalescent group (fig. 3 a) shows a rise of only $9 \mathrm{mgm}$. in blood sugar above the fasting level, and a return to this level at the end of two hours. Four tolerance tests were performed on the control group of patients. In this group the rise in blood sugar in the composite curve (fig. $3 \mathrm{~b}$ ) is $16 \mathrm{mgm}$. above the fasting level. It 
returns to within $2 \mathrm{mgm}$. of the fasting level at the end of two hours. All the individual tests were normal.

Of the sixteen cases having congestive heart failure only three (10, $11,15)$ had a positive levulose tolerance test. Every one of the fatal cases had a normal tolerance, case 6 being excluded because of mild diabetes. Three more patients $(13,16,17)$ either had a rise of $30 \mathrm{mgm}$.
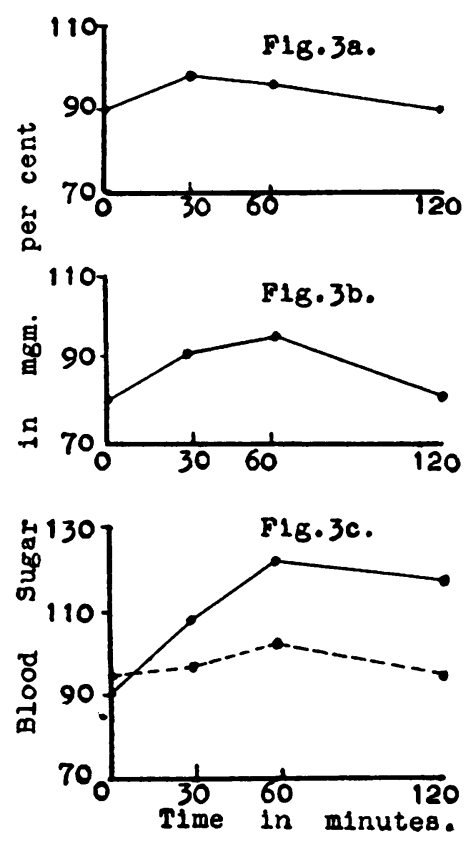

Fig. 3. Composite Curves of the Levulose Tolerance Tests

a. Fourteen convalescent patients without demonstrable liver disease. b. Control group. c. Improved group.

Solid line-control period. Broken line-after digitalis.

of blood sugar or a maximum blood sugar level of $135 \mathrm{mgm}$. per cent. Since both conditions must be fulfilled the tolerance in these three patients cannot definitely be said to be abnormal.

An important fact in the improved group is the improvement in tolerance to levulose following improvement of the case. This is illustrated by the composite of the curves performed during the control period and again after improvement (fig. $3 \mathrm{c}$ ). Every patient except 
two $(12,19)$ in the improved group showed a better tolerance coincident with clinical improvement. The two exceptions remained approximately unchanged. Lennox (27) by repeating glucose tolerance curves on a series of non-diabetic individuals, found the second curve lower in twenty-one of twenty-five subjects. He concludes that a single blood sugar curve may be without diagnostic significance and a lowered subsequent curve may not necessarily be due to experimental

TABLE 2

The occurrence of positive liver function tests

\begin{tabular}{c|c|c|c|c|l}
\hline Case & $\begin{array}{c}\text { Increase in } \\
\text { serum } \\
\text { bilirubin }\end{array}$ & $\begin{array}{c}\text { Increase in } \\
\text { urobilogen }\end{array}$ & $\begin{array}{c}\text { Retention } \\
\text { of bromsul- } \\
\text { phalein }\end{array}$ & $\begin{array}{c}\text { Levulose } \\
\text { tolerance } \\
\text { test }\end{array}$ & Group \\
\cline { 1 - 3 } & 0 & 0 & 0 & 0 & Control \\
\cline { 2 - 3 } 2 & 0 & 0 & + & 0 & Control \\
3 & 0 & 0 & 0 & 0 & Control \\
4 & + & + & + & 0 & Died \\
5 & + & + & + & 0 & Died \\
6 & 0 & 0 & + & D & Died \\
7 & + & + & + & 0 & Unimproved \\
8 & + & + & + & 0 & Improved \\
9 & + & + & + & 0 & Improved \\
10 & + & + & + & + & Improved \\
11 & + & 0 & 0 & + & Improved \\
12 & + & 0 & 0 & 0 & Improved \\
13 & + & 0 & + & 0 & Improved \\
14 & + & + & + & 0 & Improved \\
15 & 0 & 0 & 0 & + & Improved \\
16 & + & + & + & 0 & Improved \\
17 & + & 0 & + & 0 & Improved \\
18 & + & + & + & 0 & Improved \\
19 & 0 & 0 & 0 & 0 & Improved \\
\hline Total positive... & 13 & 9 & 12 & 3 & \\
Per cent positive.. & 81 & 56 & 75 & 19 & \\
\hline
\end{tabular}

or therapeutic procedures instituted between the first and second test. In his twenty-five cases the average rise in blood sugar on first determination was $65 \mathrm{mgm}$., while the average rise on the second was 60 mgm., and on the third $50 \mathrm{mgm}$. This represents a fall of less than 10 per cent on the second, and 23 per cent on the third determination. In this present group the rise of the composite curve during the control period was $31 \mathrm{mgm}$., and following improvement a rise of $7 \mathrm{mgm}$. 
This represents a fall of 75 per cent. If instead we take the rise of sugar in each curve we get an ayerage rise of $35.6 \mathrm{mgm}$. compared to $14 \mathrm{mgm}$. following improvement. This is a 60 per cent improvement. It seems therefore that the improvement in the levulose tolerance is the result of an improved carbohydrate metabolism coincident with the general improvement of the patient.

\section{SUMMARY AND CONCLUSIONS}

1. The frequency of clinical jaundice in a series of 231 patients with congestive heart failure was observed to be 2.1 per cent.

2. Jaundice in congestive heart failure may be of either the obstructive or non-obstructive type.

3. The results of this study (table 2) show that fifteen of the sixteen patients (93 per cent) had some alteration in liver function.

4. No characteristic type of liver dysfunction in chronic passive congestion was found. Three subjects $(6,12,15)$ showed only one abnormal response to liver function tests. Only one subject (10) showed all four tests abnormal.

5. No parallelism between degree of heart failure and impairment of liver function could be noted in individual cases. Patients die showing little alteration in liver function. Patients improve showing marked functional liver impairment. Patients with marked congestive failure may show no liver dysfunction. As a group there is, perhaps, a parallel between the changes in liver function and the degree of edema and size of the liver.

6. Any liver dysfunction induced by an attack of chronic passive congestion is apparently not permanent. Liver dysfunction still in evidence after recovery from an attack of chronic passive congestion probably indicates an independent liver impairment.

The writer wishes to thank Professor H. C. Smith, Dr. John Wyckoff, Dr. Mills Sturtevant and Dr. Joseph E. Connery for their advice and criticism during this investigation.

\section{BIBLIOGRAPHY}

1. van den Bergh, A. A. H., and Snapper, J., Deutsch. Arch. f. klin. Med., 1913, cx, 540. Die Farbstoffe des Blutserums. 
2. Lepehne, G., Ergebn. d. inn med. u. Kinderh., 1921, xx, 221. Pathogenesis des Ikterus.

3. Eppinger, H., In Kraus u. Brugsch, Handb. spez. Path. u. Therap., inn. Krank. 1923, vi, part 2, 293. Der Ikterus bei Herzfehlern (cyanotischr Ikterus).

4. Feigl, J., and Querner, E., Ztschr. f. d. ges. exp. Med., 1919, ix, 153. Bilirubinämie 9:153, 1919.

5. McNee, J. W., Quart. J. Med., 1922, xvi, 390. Critical Review, Jaundice. A Review of Recent Work.

6. Fishberg, A. M., J. Am. Med. Assoc., 1923, lxxx, 1516. Jaundice in Myocardial Insufficiency.

7. Andrews, C. H., Quart. J. Med., 1924, xviii, 19. A Clinical Study of van den Bergh's Test in Jaundice.

8. Schiff, Leon, Arch. Int. Med., 1927, xl, 800. Serum Bilirubin in Health and in Disease.

9. Matthes, M. E. R., Textbook of Differential Diagnosis of Internal Medicine Translated by Held and Gross. Philadelphia, 1925.

10. Schottmüller, H., Munch. med. Wchnschr., 1914, lxi, 230. Ueber Ikterus im allgemeinen und bei Extrauteringravidität im besonderen.

11. Libman, E., Cited by Fishberg, A. M., 6.

12. Keefer, C. S. and Resnik, W. H., J. Clin. Invest., 1926, ii, 375. Jaundice Following Pulmonary Infarction in Patients with Myocardial Insufficiency. I. A Clinical Study.

13. Resnik, W. H., and Keefer, C. S., J. Clin. Invest., 1926, ii, 389. Jaundice Following Pulmonary Infarction in Patients with Myocardial Insufficiency. II. An Experimental Study.

14. Resnik, W. H. and Rich, A. R., Cited by Resnik and Keefer, 13.

15. Meakins, J. J. Clin. Invest., 1927, iv, 135. Distribution of Jaundice in Circulatory Failure.

16. Page, I. H., Am. J. Med. Sci., 1929, clxxvii, 273. Ipsolateral Edema and Contralateral Jaundice Associated with Hemiplegia and Cardiac Decompensation.

17. Wallace, G. B., and Diamond, J. S., Arch. Int. Med., 1925, xxxv, 698. The Significance of Urobilogen in the Urine as a Test for Liver Function.

18. Piersol, G. M., and Rothman, M. M.. J. Am. Med. Assoc., 1928, xci, 1768. Practical Value of Liver Function Tests.

19. Serby, A. M., and Bloch, Leon, Am. J. Med. Sci.. 1928, clxxvi, 367. Liver Function as Determined by Bromsulphalein in Seventy-Six Cases.

20. Epstein, N. N., Delprat, G. D., and Kerr, W. J. J. Am. Med. Assoc., 1927, Ixxxviii, 1619. The Rose Bengal Test for Liver Function.

21. Ottenberg, R., Rosenfeld, S., and Goldsmith, L., Arch. Int. Med., 1924, xxxiv, 206. The Clinical Value of the Serum Tetrachlorphenolphthalein Test for Liver Function.

22. King, G., Lancet, 1927, i, 385. Study of Levulose Tolerance Test for Hepatic Insufficiency. 
23. Tallerman, K. H., Quart. J. Med., 1923, xvii,37. The Levulose Test for Liver Efficiency and an Investigation of the Hepatic Condition in Pregnancy.

24. Hall, W. W., J. Lab. and Clin. Med., 1927, xii, 529. The van den Bergh Reaction for Serum Bilirubin with Notes on Interpretation and Technic.

25. Rosenthal, S. M., and White, E. C., J. Am. Med. Assoc., 1925, lxxxiv, 1112. Clinical Application of the Bromsulphalein Test for Hepatic Function.

26. Folin, O., and Wu, H., J. Biol. Chem., 1920, xli, 367. A Simplified and Improved Method for the Determination of Sugar.

27. Lennox, W. G., J. Clin. Invest., 1927, iv. 331. Repeated Blood Sugar Curves in Non-Diabetic Subjects. 